\title{
Correction to: The Palgrave Handbook of Steam Age Gothic
}

\author{
Clive Bloom
}

\section{Correction to:}

C. Bloom (ed.), The Palgrave Handbook of Steam Age Gothic, https://doi.org/10.1007/978-3-030-40866-4

The original version of the book was inadvertently published with a missing reference Webb, 2010, in Chapter 31 and an incorrect chapter author surname "González, Antonio Alcalá" instead of "Alcalá González, Antonio" in Chapter 44. The corrections to the book have been updated with the changes.

The updated versions of these chapters can be found at https://doi.org/10.1007/978-3-030-40866-4_31

https://doi.org/10.1007/978-3-030-40866-4_44 